\title{
Perder el sýmbolon. A propósito de un allanamiento
}

\section{Losing the symbol. About a breaking into and entering}

\author{
GUILLERMO MORENO TIRADO \\ (Universidad Complutense de Madrid)
}

\begin{abstract}
Resumen: En este trabajo se analiza el apartado “a” del parágrafo 72 del curso de Heidegger Los conceptos fundamentales de la metafísica. Mundo, finitud, soledad de 1929-30, interpretando que la lectura de Heidegger del problema del "suceder símbolo" en Aristóteles puede ser un recurso para exponer en qué sentido nuestro punto de partida para la reflexión sobre el lenguaje tiene que ser el de la lingüística, a pesar de que esta reflexión termine mostrando que esta ciencia no puede constituirse como fundamento último del problema del lenguaje. A tal circunstancia la llamamos "perder el sýmbolon" por cuanto nuestro punto de partida presupone que no hay "secuencias lingüísticas" marcadas de antemano, siendo justamente esa marca lo que indica el "suceder símbolo”. Este trabajo interpreta, a modo de conclusión, que el problema del lenguaje se nos presenta como un fenómeno de allanamiento simbólico.
\end{abstract}

Palabras Clave: Heidegger, símbolo, allanamiento, Aristóteles, lenguaje

\begin{abstract}
In this paper, section "a” of paragraph 72 of Heidegger's course The Fundamental Concepts of Metaphysics. World, Finitude, Solitude of 1929-30 is analysed, interpreting that Heidegger's reading of the problem of the "happening symbol" in Aristotle can be a resource to expose in what sense our starting point for the reflexion on language has to be that of linguistics, in spite of the fact that this reflexion ends up showing that this science cannot be constituted as the ultimate foundation of the problem of language. We call this circumstance "losing the sýmbolon" because our starting point presupposes that there are no "linguistic sequences" marked beforehand, and it is precisely this mark that indicates the "happening symbol". This paper interprets, by way of conclusion, that the problem of language is presented to us as a phenomenon of symbolic breaking into and entering.
\end{abstract}

Keywords: Heidegger, symbol, breaking into and entering, Aristotle, language

\section{A modo de introducción: cuestiones conocidas}

Es conocido que Heidegger interpreta que Aristóteles se ve en la tesitura de tener que construir una argumentación acerca del lógos para distinguir, entre los posibles lógoi, uno que quede reservado para la theoría, a saber, el lógos apophantikós ${ }^{1}$. De esa interpretación interesa

1 Doy solo dos referencias, pues la cuestión aparece en muchos lugares de su obra, la primera, del curso Lógica. La pregunta por la verdad, de 1925/26 (GA 21, pp. 127-195), y la segunda, del curso de Los conceptos fundamentales de la metafísica de 1929/30, donde la cuestión está dirigida a preguntarse en qué consiste, además del decir enunciativo, la “cópula”, (GA 29/30, pp. 441-507); aprovecho para referir al lector a los trabajos de Alejandro Vigo recogidos en Juicio, experiencia, verdad. De la lógica de la validez a la fenomenología, especialmente al dedicado a la sýnthesis y la diaíresis en Husserl y Heidegger desde Aristóteles (Vigo, 2013, pp. 229-265); véase también Vigo, 2012. Por otro lado, para una muestra del trabajo de Heidegger sobre Aristóteles, cf. Volpi, 1984; Taminiaux, 
recordar que esta distinción no es meramente frente a otros lógoi que estarían reservados para otra cosa, sino que, de hecho, también el tipo de lógos que es apophantikós pertenece esencialmente a esos supuestos "otros". El "otro" adjetivo para caracterizar el lógos es

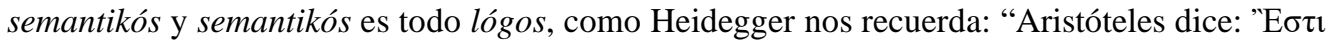

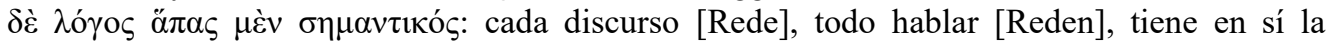
posibilidad de dar a significar algo, aquello que nosotros entendemos” (GA 29/30, p. 443). Esta "posibilidad de dar a significar algo" es un asunto del que ya había hablado Heidegger en otros lugares, como por ejemplo en el curso sobre el Sofista de Platón, donde se hace explícito que ese "significar algo" en Grecia refiere a lo que el término griego hermeneía mienta, a saber, que

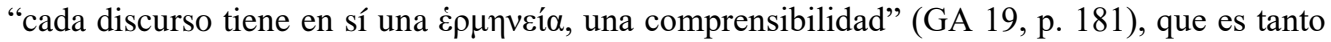
como decir que todo lógos es lógos en la medida en que señala el estar trabado en alguna significación de modo que, él mismo, significa algo interno a esa significación; de ahí que el lógos sea, ante todo, semantikós y que, por tanto, la distinción que establece el apophantikós no implique que los otros lógoi estén reservados para algo en concreto, sino que lo que se marca es ese tipo especial de lógos que además de señalar o significar (semaínein), hace ver o muestra (el verbo sería deloŷn) el significar mismo, esto es, lo que el lógos es en cuanto tal, porque es en él en el que ocurre la tematización, la distancia del “reunir que junta separando". Y, sin embargo, también es cierto -y también lo dice Aristóteles y lo cita Heidegger- que de los lógoi que no son apophantikoí se ocupa la poietikês y la rhetorikês. Esta argumentación responde, como también es muy conocido, a una problemática interna del mundo griego que es consecuencia de qué mundo histórico es precisamente ese, a saber, la problemática de la falsedad (el disimulo o el simulacro), de qué quiere decir que sea posible un discurso falso y de cómo se distinguen o, más bien, en qué radica esa distinción y dónde (en qué contexto) puede notarse (a través de qué decires).

Sin pretender ahora extenderme mucho en esta discusión, el problema está ligado a la identificación que fenomenológicamente puede argumentarse que hay en la Grecia arcaica y clásica entre el decir y la cosa, entre el decir y la verdad (cf. Aubenque, 2013, pp. 94-134)². En principio (y resumiendo mucho), no hay distancia entre el comparecer de la cosa como la cosa que es y el decir esa misma cosa, de modo que tampoco la hay entre decir con verdad y simplemente decir algo. Que no haya esa distancia en principio es tanto como afirmar que lo obvio para un griego arcaico o clásico es que "decir algo" es “decir con verdad” y "decir algo" que no es verdad quiere decir simplemente "no decir”, no haber dicho nada en absoluto. Es esta situación de partida la que pone al griego arcaico y clásico ante la tesitura de tener que preocuparse acerca de cómo es posible, a pesar de todo (digamos, a pesar de lo que para él es obvio), que alguien pueda “decir algo” sin verdad. El problema del griego antiguo no está tanto

1989; Segura Peraita, 2002; 2015; 2018; Courtine, 2018; Vigo, 2008, pp. 17-38, pp. 117-142 y pp. 213-230. A propósito de la lectura del lógos en los cursos de los años 20, puede encontrarse un buen resumen de las cuestiones (aunque algo superficial y reduccionista en algunos puntos) en el trabajo de Scott M. Champbell, "Revelation and Concealment in the Early Heidegger's Conception of $\Lambda$ ó $\varsigma^{\prime}$ " (Champbell, 2007). Por otro lado, véase también: Martínez Marzoa, 1996; Jiménez Redondo, 1997; Chillón, 2015 y 2014, pp. 61-83. Por otro lado, lo que a continuación presento es una adaptación de los dos primeros apartados del capítulo 15 de mi trabajo de Tesis doctoral (Moreno Tirado, 2020, pp. 353-364). Allí puede encontrarse todo el contexto de discusión, sin embargo, este trabajo tiene autonomía propia y sus planteamientos alcanzan lugares que solo se pudieron sugerir en aquel otro trabajo.

2 En las primeras páginas referidas, Aubenque expone el problema con el que se encuentra discutiendo Aristóteles, cuyo punto de partida es que "lo que se dice, se dice, y lo que no, no”. "Allí donde nuestras traducciones [de los diálogos platónicos, por ejemplo] ponen «¿Digo algo acertado?», o cosa parecida, el texto griego tiene simplemente «¿digo algo?»; en griego al decir como tal le pertenece ser alethés, y el verdadero problema, el que trae de cabeza a más de un griego, es el de cómo puede entonces un decir, siendo en verdad decir, ser pseudés; y el griego se crea en efecto ese problema, es decir, no tiene más remedio que admitir que, en efecto, el decir puede ser también pseudés, pero esto le ocurre al griego por algo bien diferente de la obviedad que tal dualidad tiene para el moderno, a saber: al griego le ocurre porque reconocer tò alethés, admitirlo como relevante, es lo mismo que reconocer la posibilidad de lo contrario” (Martínez Marzoa, 2001, p. 61).

Studia Heideggeriana, Vol. VIII, 2019 
en cómo se distingue lo que es verdad, sino en cómo se distingue lo que no lo es y, sobre todo, qué estatuto tiene eso que en rigor no es nada en absoluto y en qué contexto sale a la luz nítidamente. Este, digo, es el problema griego expresado desde estos recursos, no y nunca el nuestro, pues la obviedad de la que partimos nosotros es otra; es más, es radicalmente la otra posición, a saber, el que se presuponga (se tenga como obviedad) que hay una distancia infranqueable entre el decir y lo dicho, entre la cosa y la verdad, de modo que lo que nos genera un problema no es saber cómo es posible mentir, sino cómo es posible decir con verdad, decir algo con validez, y ello, a pesar de que también para nosotros puede terminar habiendo una identificación entre las cosas y la verdad.

Pues bien, según Heidegger, Aristóteles se enfrenta precisamente a ese problema cuando se dedica a construir "sistemáticamente" una distinción entre un lógos que además de significar, de señalar la normal imbricación que un griego antiguo tiene con las cosas, muestra o hace ver de manera que en él quepa distinguir precisamente lo falso como falso y lo verdadero como verdadero. Este tipo de lógos hace esta distinción porque todo lógos de este tipo muestra al mismo tiempo el estatuto mismo del lógos, es decir, muestra eso que el lógos es en general, a saber, el estar imbricado con las cosas tal que haya significación y, por tanto, en él cabe dirimir si esa imbricación lo es con las cosas presentes ahí delante o con su disimulo. La distinción entre tò alethés y tò pseudés es posible en el lógos apophantikós porque, en virtud de haber distinguido este lógos, también se distingue entre la phýsis y el lógos, de modo que un lógos pueda ser perfecto lógos y estar en el disimulo, es decir, que un lógos puede ser perfecto lógos sin tener que ser verdadero lo en él dicho.

De momento no voy a seguir ocupándome de esto, sino que, tomando pie en ello, voy a pasar a considerar algo que lo antecede y que se encuentra en el curso de 1929-30, Los conceptos fundamentales de la metafísica. Mundo, finitud, soledad. En el apartado “a)” del parágrafo 72 (GA 29/30, pp. 442-448), encontramos una exposición de cierta manera que tiene Aristóteles de expresar cómo sabemos que está ocurriendo algún lógos semantikós que, si bien no tiene un tratamiento sistemático en la obra de Heidegger, puede sostenerse (o formularse la hipótesis interpretativa de) que vertebra el mar de fondo de muchos de los textos que hablan directa o indirectamente del lenguaje y, sobre todo, que pone sobre aviso acerca de qué puede haber ocurrido para que nuestro punto de partida sea justo el opuesto. Pero, no solo eso, sino que, además -y de esto es de lo que me quisiera ocuparme- esa exposición presenta ciertos paralelismos con los fundamentos de la refundación de la lingüística en el siglo XX y es una clave interpretativa tanto para comprender por qué surge, como para mostrar uno de los problemas filosóficos que arrastra.

Se verá -y este es, digamos, el objetivo de este trabajo- que las diferencias entre la exposición desde Heidegger del motivo aristotélico y la exposición resumida de la fundamentación de la lingüística tardomoderna dependen de que eso que Heidegger expone de Aristóteles se haya perdido, haya quedado irremediablemente atrás, de modo que es justamente esto lo que ha permitido que surja esa fundamentación; pero, también, que es el trabajo de Heidegger sobre el motivo aristotélico lo que nos permite dar respuesta a un problema que acompaña a esa fundamentación.

\section{Hónta génetai sýmbolon y katà synthéken}

Pues bien, todavía en Aristóteles, según lo que se ha esbozado, Heidegger nos dice que lo obvio es que: "El discurso da a entender y exige comprensión. Por su esencia, se dirige al libre comportamiento y actuar [o: habérselas, Handeln] de los hombres entre sí” (GA 29/30, p. 443), lo cual, nos continúa comentando Heidegger, es caracterizado por Aristóteles no como el funcionar del aparato fonador “que, puesto en actividad, inevitablemente logra algo" (GA 29/30, 
p. 444), sino como katà synthéken (más adelante aparecerá la traducción que da Heidegger de

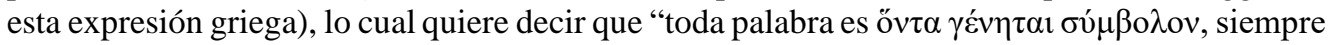
que sucede un símbolo” (GA 29/30, p. 444) ${ }^{3}$. ¿Qué quiere decir en el comentario de Heidegger al texto aristotélico la expresión katà synthéken y hónta génetai sýmbolon?

La explicación de Heidegger de la voz griega sýmbolon, como es habitual, muestra una fuerte resistencia a aceptar la traducción más o menos corriente: “símbolo”. La interpretación de Heidegger pretende asumir con más fuerza la distancia entre la lengua griega y las lenguas modernas. Así, nos encontramos que en este tramo del curso se nos dice que sýmbolon, en el mundo griego, significa, en general, "amontonar lo uno con lo otro" en el sentido de que entre ellos haya cohesión, encaje; de ahí que Heidegger insista en que significa lo mismo "que la juntura [o: fuga, die Fuge], la soldadura, la articulación, donde lo uno no solo está llevado junto a lo otro, sino que se mantienen mutuamente [el uno en el otro, aneinandergehalten], de modo que el uno viene con el otro [aneinander paßt]" (GA 29/30, p. 445). Para ilustrar esta significación general, Heidegger emplea un ejemplo clásico: el anillo que dos amigos se dividen entre sí y dejan, cada uno su mitad, en herencia a sus hijos, tal que al encontrarse estos, se reconocen como "hermanados" por los padres; el anillo es el sýmbolon de dicha amistad en la medida en que, dividido en dos mitades, "junta”, "suelda” o "articula” la relación de amistad entre ellos.

En este mismo ejemplo se muestran las reservas de Heidegger para con la traducción corriente, pues esta habría comportado la comprensión de que, por lo general, nosotros interpretemos esto diciendo algo así como que ese anillo dividido simboliza la relación de amistad que los hijos heredan de los padres, la cual es reconocida en el encuentro y puesta en común de las dos mitades, donde por "simboliza” entendemos que una cosa (las dos mitades del anillo) representa a la otra (la relación de amistad que los hijos heredan de los padres). Sin embargo, es este significado (que es el mismo que el medieval aliquid stat pro aliquo; por ejemplo, véase: Bühler, 1999, pp. 40-42) el que es cuestionado por la interpretación heideggeriana, ya desde el ejemplo, en lo siguiente.

No se trataría de que lo que el griego ande diciendo sea una "representación de", sino que, para el griego, el sýmbolon es el andar ocurriendo un estado de cosas que consiste en que haya un "convenir [entre dos que no tienen por qué tener nada en común] en un mantenerse juntos y un mutuo mantenerse (comparar)” (GA 29/30, p. 446). La palabra entre paréntesis, en el alemán, es Vergleichen, en cuyo campo semántico se incluye también "el acuerdo”; no se trata aquí de que el "mutuo mantenerse" (Zu-einanderhalten) sea una comparación, como se compara la altura de un edificio con otro, sino que ambos son en un "acuerdo", en un acontecer de dos que, reconociéndose como irreductiblemente dos, son en este mantenerse juntos, porque el uno está acordado con el otro y el otro con el uno tal que mutuamente se mantienen acordes, y ello sin que como tal generen una tercera cosa. El sýmbolon, por tanto, no es una tercera cosa entre dos,

\footnotetext{
Debe tenerse en cuenta que el uso de la palabra "génesis" en este texto no tiene el significado que, a partir del Idealismo alemán, especialmente de Fichte, adopta; significado que es, por otra parte, el corriente, a saber, provenir de, en el sentido de "derivar de". Extraemos de la entrada del diccionario de A. Bailly los siguientes sentidos para la palabra: I. fuerza productiva, causa, principio, origen, fuente de vida, producción, generación, creación; producción de objetos manufacturados por el hombre (vestimenta, etc.); producción de cosas abstractas (virtudes, cualidades, etc.); El Génesis, título del primer libro del Pentateuco en la Septuaginta; 2. origen; de dónde, nacimiento, día del nacimiento; 3. Acción de devenir, de llegar a ser; II. referido a todo ser creado, y de ahí: 1. el conjunto de seres creados, la creación; 2. raza, especie o suerte de animal, (en particular para las personas), referido a familia; 3. (con la idea de duración) generación, edad; III. órganos genitales (Bailly, 1950, p. 395); Heidegger asume como traslación del término griego al alemán geschehen, literalmente: suceder, que tiene aquí el mismo campo semántico que wesen, luego, por lo tanto, quiere decir "tener lugar”, "acontecer” y, ello mismo, en relación con el sentido fuerte de historia del ser. Así pues, la génesis de esto o aquello es su "tener lugar”, su "llegar a ser (lo que es)", su "suceder”, es decir, se trata de otro término para expresar el vuelco del llegar a la presencia en el mundo griego.
} 
ni el que una esté tomada por la otra, sino el que haya dos tal que entendiéndose como dos, suceden ambas como dadas conjuntamente.

Esta conjunción, que, al constatarse, al ser reconocida, es ya indisoluble, se debe a que sucede algo (que, sin embargo, no es nada, no es cosa alguna) entre ellos; es, insisto, a este "algo (que no es cosa alguna) entre ellos” a lo que se llama sýmbolon y por eso Heidegger se refiere a ello como "juntura”, "soldadura” o “articulación”. A que ande ocurriendo esta particular articulación es a lo que Aristóteles se refiere con que esa articulación sea katà synthéken en oposición a katà phýsin. Así, que sea sýmbolon lo que caracteriza al lógos qua lógos, quiere decir que lo que menos importa es qué ocurra en el aparato fonador o, siguiendo con el ejemplo, si se trata de anillos de tal o cual material o de si los hermanados por los padres tienen esta o aquella edad, etc.; lo importante es que ese suceder no surge como surge lo que surge desde sí mismo (no es el tipo de suceder que se observa en el crecimiento de una planta, de un animal, en el cambio de lugar de una piedra, etc.), sino uno que sucede, digámoslo así, por composición.

Lo que Aristóteles dice que es katà synthéken (el que suceda un "mantenerse juntas y un mutuo mantenerse" de dos cosas que, en principio, no acontecen juntas y sin que tenga por qué tener nada en común) lo "traduce" (interpretando) Heidegger en este curso diciendo que es un Übereinkommen que, quizá, aligeradamente traduciríamos (y entenderíamos) en castellano como un convenir, pero vamos a ver que la cuestión no es tan sencilla.

Übereinkommen quiere decir, en este contexto y según la interpretación expuesta, un venirjuntos más allá (über-, trans-) de si a ese venir-juntos, si a esta articulación, le podía acontecer o no por sí misma a una y/u otra cosa por alguna razón de tipo "natural” (o "material”) inherente a ellas; expresa, por tanto, un venir conjunto que no responde a nada más que al haber ocurrido ese venir conjunto, que está, por tanto, más allá de cualquier otra explicación que no sea apelar a su composición. Por consiguiente, lo que se expresa con el vocablo depende de algo que sucede

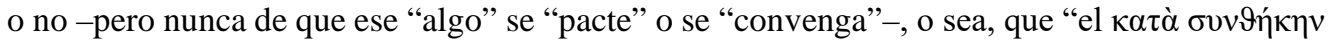

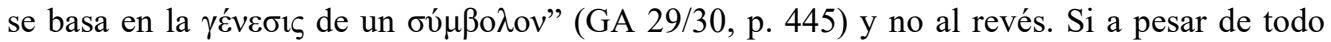
queremos mantener la palabra "convenio" para la traducción, entonces no estará demás añadir que es un convenio muy particular que consiste en constatar que más allá de si una de las partes o ambas podían lograr acordarse entre sí (por algún rasgo interno de parentesco de algún tipo), ocurre el acuerdo (les sobreviene, digamos, sin más motivo, arbitrariamente) tal que vienenjuntas, de modo que su venir, su comparecer, es si y solo si comparecen juntas. A ese tipo de comparecencia es a lo que también nos referimos cuando decimos que hay significado; que lo hay no porque aparece "por fin" el significado, sino porque se constata que se está envuelto en significación o significaciones y que estas se expresan en la medida en que "sucede símbolo", o sea, en que suceden composiciones, articulaciones, junturas, esto es, lógos ${ }^{4}$.

Pues bien, teniendo en cuenta que esto caracteriza el lógos semantikós, lo que se acaba de exponer constituye las razones por las cuales Heidegger afirma que "discurso y palabra [en Grecia] están en el suceder del símbolo sólo si y en tanto que sucede un convenir y un mantenerse juntos” (GA 29/30, p. 446). Ese suceder, por tanto, es la condición de la posibilidad del discurso en sentido griego. No la tematización, sino el componer, esto es, el que suceda eso mismo. Al discurso o decir en general, se dedica, entonces, la poesía y la retórica y, en la medida en que lo hacen son decir en sentido relevante, pero no un mero "tipo" de decir, sino el decir que es a ultranza decir (porque consiste a ultranza en componer $^{5}$ ) y que la teoría puede mostrar

4 “Nuestra esencia de antemano es tal que entiende y conforma comprensibilidad. Porque nuestra esencia es así, por eso las emisiones que nosotros también producimos pueden tener un significado. El significado no crece a los sonidos, sino a la inversa, solo a partir de significados ya conformados y que se conforman se conforma la acuñación del sonido. Si bien el $\lambda o ́ \gamma o \varsigma$ es $\varphi \omega v \eta ́$, no lo es primariamente y luego otra cosa, sino a la inversa, primariamente es

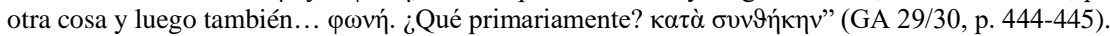

5 Y son notorias dos cosas: 1) que synthétes sea el que escribe organizando las palabras con arte (véase la entrada en el diccionario: Bailly, 1950, p. 1860), esto es, tal que ellas misma comparecen en su presencia, en cuanto tal; y, 2) que sea precisamente "poeta” (y, quizá, “retórico”, y este sería un lugar de discusión muy problemático) como un 
porque en el tipo de decir en el cual tiene lugar (lógos apophantikós) se muestra temáticamente lo que en la poesía y en la retórica anda ocurriendo de manera obvia, no temáticamente.

\section{Nuestro punto de partida}

Ahora bien, todo esto que hemos expuesto está referido a la Grecia arcaica y clásica pero no es exactamente lo que nos ocurre a nosotros. Nosotros (modernos $\operatorname{tardíos}^{6}$ ) no partimos de la obviedad de que el decir que a ultranza es decir es el que tiene lugar en composiciones (de poesía o retórica), sino que el decir que tiene el rango de obviedad es precisamente aquel que Aristóteles se tiene que esforzar por conceptualizar, el decir que muestra y en su mostrar determina. Un decir que, aunque en su uso más depurado es científico o jurídico, tiene lugar todos los días, que es el decir que se entiende que anda ocurriendo de manera trivial -y que sea ese el que de modo depurado reconocemos como científico o jurídico dice ya mucho de nuestro mundo-. Este decir puede seguir llamándose apofántico (ya sin necesidad de mantener transliteraciones del griego) o simplemente proposicional, enunciativo o predicativo, y es el tipo de decir del que Heidegger se ha ocupado de destruir fenomenológicamente para sacar a la luz el fenómeno del cómo hermenéutico (das hermeneutische “als”). Podemos afirmar que nuestro punto de partida es precisamente el tipo de decir que acontece como proposicional, enunciativo o predicativo sin que ello suponga un menoscabo de todos aquellos otros "tipos de decir" (o quizá, más bien, de oraciones) que, además, seguimos reconociendo, pero que los reconocemos porque se apartan de este, que es, por así decir, lo que se presupone como el que va de soi. Evidentemente, no "va de suyo" y ni siquiera, como también se extrae del trabajo de Heidegger, es el que da fundamento al decir en general, pero esto no quita que sea, de todas formas, el que inmediatamente se entiende como el tipo de decir obvio, el tipo de decir cero o no marcado, el que no necesita de más aclaración.

Pues bien, esta constatación debe servirnos ahora para notar un parentesco que hay en el modo como, partiendo de este presupuesto, la lingüística tardomoderna se fundamenta ${ }^{7}$, y el que acabamos de recordar que se halla en la interpretación de Heidegger de Aristóteles, pero que se diferencia precisamente en que es esencialmente moderno, es decir, en que tiene lugar y solo ha podido tener lugar en el tiempo histórico que filosóficamente llamamos "Modernidad", y ello en virtud de la diferencia respecto al punto de partida que se acaba de recordar. Este análisis se lleva a cabo en la Modernidad tardía para lograr algo que, tangencialmente, se puede considerar que la interpretación de Aristóteles de Heidegger también logra, a saber, la definición clara y autónoma de la lengua. Digo, “tangencialmente”, porque Aristóteles lo que está haciendo es describir el carácter de todo lógos qua lógos (que sea semantikós), y lo está haciendo para mostrar que solo con ese carácter no se soluciona el problema por el que él mismo se empeña en hacer estos análisis ${ }^{8}$. Eso que con esta interpretación de Aristóteles se logra entretanto es tematizar qué es el "suceder símbolo", por tanto, qué es eso de "símbolo"; y ya hemos dicho que ese suceder es siempre katà synthéken, esto es, por un venir juntas de dos "cosas" más allá de si vendrían "naturalmente" juntas o no ${ }^{9}$. El sýmbolon, por tanto, surge no de la

griego antiguo llamaría al que compone de modo relevante, esto es, de tal modo que lo que comparecen son las cosas mismas en su presencia.

Sobre “tardomodernidad”, cf. Martínez Marzoa, 2019, pp. 95-110.

Nos referimos a la lingüística que surge en confrontación con el Curso de lingüística general de Ferdinand de Saussure (Saussure, 2005).

8 Recuérdese que ese problema era acerca de cómo es posible que tenga lugar el discurso falso y, por tanto, en dónde se puede hacer la distinción.

9 Es muy importante el entrecomillado a "cosas” y a "naturalmente” porque cuando un griego antiguo (como Aristóteles, por ejemplo) se refiere a esto, los vocablos utilizados estarían muy lejos de poder ser traducidos automática y exhaustivamente a vocablos en lenguas modernas, pues “cosa” es para un griego antiguo (sin importar 
“espontaneidad de lo que surge por sí mismo”, sino de algo que solo ocurre para aquella forma de zoé (o aquel zoôn) que "tiene” o se mueve ya siempre en lógos, es decir, en eso que todo lógos tiene solo por ser lógos, a saber, lo que también se pude decir con el verbo semaínein (significar) o con el vocablo hermeneía (comprensión) y que Heidegger suele decir como comprensión de ser o del sentido de ser. Eso es lo que queda tematizado con la interpretación de Heidegger de Aristóteles y que se reconoce cuando se reconoce esa relación de dos "cosas" que siendo precisamente dos acontecen tal que una remite a la otra y la otra a la una.

El parentesco tardomoderno que encontramos en la lingüística está en que esta ciencia se ve en la tesitura de tener que definir cierta relación entre dos "aspectos" (o elementos de dos conjuntos) que no tienen por qué tener nada en común (es más, no lo tienen, nada motiva su vínculo, este es, por tanto, arbitrario) tal que solo porque esa relación ocurre, puede considerarse que están teniendo lugar no separadamente, sino como el comparecer de una unidad. Ahora bien, se diferencia radicalmente en que esta unidad de dos caras se ha tenido que encontrar (que construir axiomáticamente, es decir, mediante un proceso similar al que se utiliza en matemáticas) para que esta ciencia pueda reivindicar su ámbito autónomo de estudio, es decir, su propio objeto, su propio método, etc. Ello logra decir qué añade el adjetivo "lingüístico" a "signo" y tiene como resultado no solo conceptualizar lo que es el signo lingüístico, sino sobre todo lo lingüístico y la entidad de la cual se tiene que ocupar (en tanto que ciencia moderna) la lingüística.

Este esfuerzo teórico, digo, tiene como punto de partida lo que desde el discurso filosófico (por ejemplo, el de Heidegger para hablar del tiempo vulgar) se suele denominar el "continuo ilimitado” (siguiendo el ejemplo de Heidegger, el continuo ahora, ahora y ahora) y cuyo problema no es, como en la Grecia antigua, cómo es posible que una cosa sea falsa, sino cómo es posible que una cosa sea verdadera, es decir, el problema no es encontrar cosas que a ultranza sean cosas y no simulacros, sino cómo saber por dónde cortar en ese continuo que sigue hacia un lado y hacia el otro y en el cual todos los puntos están de antemano descualificados respecto de todos los demás. La solución, como se sabe, es observar que para que un corte sea válido debe corresponder con otro corte en otro conjunto que guarde (hasta cierto punto) isomorfismo; en la Modernidad no se trata de encontrar cosas cualificadas sino de determinar los cortes en el continuo que son cortes relevantes en otro continuo igualmente ilimitado y que solo porque corresponden biunívocamente entre sí, se aceptan, efectivamente como cortes válidos ${ }^{10}$.

Este criterio es el mismo con el que la lingüística procede. Para definir su entidad, el signo lingüístico, la lingüística procede definiendo la relación biunívoca de un elemento de un conjunto ordenado, al menos, por pares binarios de oposiciones con un elemento de otro conjunto ordenado del mismo modo (pero no igual) tal que, ninguno de los conjuntos tenga otra cosa en común que esa misma relación biunívoca (cf. Martínez Marzoa, 1999, pp. 81-84, y 2005, pp. 11-16). Con ello lo que se logra definir es que la ocurrencia de uno de los elementos

qué vocablo concreto utilice) algo caracterizado principalmente porque lo evidente es que ello sea irreductiblemente lo que es, que su "ser" sea una presencia cualificada, es decir, que tengo una suerte de "dignidad propia”, de modo que no sea automáticamente reproducible ad libitum et infinitum, ni tampoco que (una cantidad de ello) pueda ser automáticamente intercambiada por (una cantidad de) cualquier otra "cosa”; y porque "natural”, que en general sería phýsis, no solo no refiere meramente al campo semántico concreto que las palabras que en lenguas modernas dicen lo mismo que la voz castellana "natural", sino que además resulta ser una de esas palabras que los dicentes expertos griegos han marcado al mismo nivel que otras para referir no a un conjunto concreto de "cosas", sino al juego mismo en el cual podría hablarse de algo así como ámbitos o conjuntos concretos de “cosas” o, con Heidegger, al “ser” (cf. GA 9, pp. 300-301, y GA 7, pp. 211-234).

10 La formulación puede también resumirse diciendo que la Modernidad se embarca en la empresa de lograr expresar todos los movimientos (en sentido amplísimo) de la materia y/o la energía, que son observables en general (ya sea a simple vista o mediante métodos de medición), en un correlato de fórmulas matemáticas; siendo esta empresa el proyecto de conocimiento o el proyecto de la ciencia moderna (cf. GA 5, pp. 75-113 y GA 7, pp. 5-65) y a la cual le corresponde una empresa jurídica de la cual Heidegger se ocupa bastante menos, pero que tiene en su horizonte garantizar todo aquello que materialmente pueda ser garantizado universalmente. 
de un conjunto es siempre la ocurrencia del otro elemento del otro conjunto, y esto es lo que le vale a la lingüística para identificar su entidad como una moneda de dos caras.

Cada una de las caras es un "aspecto" de la unidad que forman y cada una de ellas se conforma como ese "aspecto" de la unidad por apartarse de aquello que la lingüística tiene que reconocer en este punto de su fundamentación como "extralingüístico", como lo "nolingüístico" frente a lo cual ella misma se define. Para una de las dos caras, el significante o el elemento de expresión, eso "extralingüístico" son articulaciones sonoras producidas por el aparato fonador y recibidas por el aparato auditivo descriptibles físico matemáticamente tal que no se distinguen de cualquier otro sonido descriptible físico matemáticamente, lo lingüístico empezaría allí donde se distinguen claramente y su distinción depende de que aquellos cortes en las posibles articulaciones son unos u otros (en cada lengua) en la medida en que cada uno de ellos corresponde a otro corte del conjunto que constituye la otra cara. Así, para la otra cara, el significado o el elemento de contenido, eso “extralingüístico” son referencias a todo el ámbito que se presupone determinable por la física-matemática en general, pero también -y este es un problema que quedará sin discutir- referencias de sentido (lo que con Husserl llamaríamos “actos de significación” y con Heidegger “comportamientos ante-predicativos”), es decir, lo lingüístico empezaría allí donde se distinguen los cortes en el continuo ilimitado constituido por las posibles (y siempre divisibles) articulaciones de sentido por corresponder a cortes en el continuo ilimitado constituido por las posibles (y siempre divisibles) articulaciones del aparato fonador.

Como se sabe, esto obliga a la lingüística a tener que echar mano de un concepto muy señalado y que dio lugar a un movimiento intelectual, pero que el echar mano de él solo pretende hacer notar el estatuto que tienen las entidades lingüísticas frente a las otras; se trata, como se sabe, del concepto de estructura (cf. Villaverde López, 2017, pp. 109-137). La cuestión es que es de una estructura de lo que la lingüística se ocupa si es cierto (como así es) que se ocupa de sistemas de signos que funcionan como sistemas de valores puros en la medida en que sus unidades se ordenan (o se constituyen) por oposiciones negativas y relativas a todo el sistema. Ahora bien, lo que se vio en el aparatado anterior no es el equivalente aristotélico de esto (el signo lingüístico como el concepto a partir del cual la lingüística se defina a sí misma como ciencia y acota su ámbito de estudio), sino cierto "antepasado" de esto que ya no es para nada griego antiguo sino muy nuestro, o sea, que es lo que queda cuando aquello otro griego (el hótan génetai sýmbolon) ha dejado de ser, cuando la Grecia arcaica y clásica se ha perdido irremediablemente y, por tanto, ya no significa lo que significaba entonces (lo que se expuso en el apartado anterior), sino justamente esto otro que argumenta la lingüística. En otras palabras, hay signo lingüístico cuando lo que ha ocurrido es el allanamiento del sýmbolon. ¿Qué quiere decir en este caso la pérdida? ¿Por qué utilizar la expresión allanamiento del sýmbolon?

\section{Lo que queda atrás: hótan génetai sýmbolon}

Para tratar de responder a estas preguntas debemos, en primer lugar, notar lo siguiente: Aristóteles (y así lo está reconociendo Heidegger) ha especificado este “suceder símbolo” para aclarar que el lógos semantikós no ocurre por mera phýsei, o sea, por la mera phoné, sino porque la phoné implicada en el lógos es tal (a saber, semantiké), si y solo si ese lógos es katà synthéken: si y solo si la $v o z$ ocurre en tanto que sucede un mantenerse juntos de una articulación por convenio (Übereinkunft), o sea, si y solo si la voz es voz porque refiere a una significación y viceversa. Así pues, lo que Aristóteles parece estar tratando de decir es que el lógos, el "reunirseparar que mantiene junto a lo reunido", es ese sonido que es tal si y solo si es ya siempre en el suceder de un sýmbolon, esto es, en el suceder de un mantenerse-junto de "sonido" y “comprensibilidad” (dos qué no tienen nada en común), de manera que ese (o cada) "sonido" 
miente ${ }^{11}$ esto o lo otro y no quede como un mero sonido. Digamos que, allí donde hay "sonidos” que sin dejar de serlo solo son porque ocurren en medio de ese "suceder símbolo" hay lógos semantikós, esto es, discurso o palabra en general ${ }^{12}$.

Por otro lado, y todavía en el orden de responder a las preguntas anteriores, hay que recordar ahora que el punto de partida de Aristóteles es la no distinción entre lo que para nosotros es irremediablemente, por un lado, el acontecer de las cosas y, por otro, el decir (de ellas) ${ }^{13}$. Así pues, con esto Aristóteles está notando que el acontecer de las cosas es algo que solo es en la medida en que estas cosas son comprensibles, es decir, son, cada una de ellas, esta y no otra. Es en este sentido en el que decimos que para él (o sea, para la Grecia arcaica y clásica) solo con esto no se responde el problema de saber cómo cabe que un decir (siendo perfecto decir, por tanto, un acontecer de cosas) sea "falso", “engañoso", o sea, un decir que no nos ponga delante de una cosa tal y como ella acontece sino como otra. De ahí que el siguiente paso para Aristóteles sea la distinción del lógos que además de ser semantikós es apophantikós. Pero este paso terminará por arruinar la situación griega en la medida en que lo que se averigua es el reconocimiento de la irreductibilidad de cada cosa, y es esa irreductibilidad la que se va a ver descualificada, la que se va a perder, con esta distinción y la consecuente tematización del lógos apophantikós, a pesar de que es solo con este paso con el que se pone de manifiesto en qué consiste esa misma articulación.

La descripción del lógos semantikós distingue lógos de phýsis, o sea, un modo de tener lugar la articulación de otro modo también de articulación, pero con el lógos apophantikós se tematiza en qué consiste esa articulación misma, a saber, se pone de manifiesto la estructura del "en tanto que” del "algo en tanto que algo" que, sin embargo, entonces, debe valer también para describir el vuelco, la distancia que se constata como phýsis. Esto no quiere decir que se iguale el lógos apophantikós y la phýsis, sino que, por un lado, lo que se allana es la distinción entre uno y otro lógos (pues el apophantikós termina por explicar el semantikós) y, por otro lado, que es con esos lógoi con los que se tematizará la phýsis, de manera que en estos se podrá discutir si corresponden o no con la phýsis.

Al dar este paso, o sea, al tematizar lo siempre ya supuesto como lógos, se pierde la indistinción entre lo uno y lo otro, pero, a cambio, o como resultado, se distingue lógos de phýsis, decir de acontecer. La razón es que, a partir de que esto quede tematizado y ya siempre se tematice, por así decir, de antemano, se asumirá como lo obvio que todo decir es esa articulación apofántica; lo que se pierde con ello es precisamente el "suceder símbolo”, el que haya cualificadamente las cosas. Esta pérdida de la cualificación inherente a cada cosa es lo que permite a la lingüística definir la noción de signo lingüístico y, en general, fundamentarse, pues es esa pérdida la que permite entender que el vínculo no sea a cada cosa y el nombre que ella tiene, sino al sistema (de signos) observable en el referirnos a las cosas. Ahora bien, ¿no es ese referirnos a las cosas, lo que el suceder símbolo pretendía mentar?

Pues sí, era justamente eso, y por ello (y ahora respondemos a la segunda pregunta con la que terminábamos el apartado anterior), si bien lo que ha ocurrido es la pérdida de lo que esto mismo significaba en Grecia, lo que no se ha perdido, sino que más bien ha quedado salvaguardado, ha sido el fenómeno mismo del estar referidos a las cosas. Es a este doble juego al que merece la pena llamar allanamiento, pues allanar no solo significa aplanar, nivelar,

11 Heidegger utilizará también la palabra zeigen, señalar, indicar y winken, hacer o dar señas; de donde Zeichen, signo, y Winke, señal (cf. Currás Rábade, 1977).

12 "Las palabras, el discurso, suceden en y desde tal convenir con aquello que de antemano es mentable y captable en cuanto tal, con aquello sobre lo cual varios pueden y tienen que convenir simultáneamente unos con otros en tanto

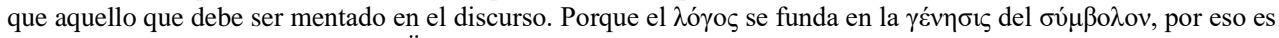

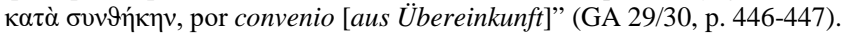

13 Recuérdese que esto no significa que Aristóteles u otro griego antiguo no distinguiera entre, digamos, alguien "hablando" y el florecer de una flor, sino que se llamaba igualmente al tipo de articulación que podía reconocerse en el florecer y aquella otra del decir; no de un dicente trivial, sino de un dicente experto. 
igualar, sino también, resolver, permitir que otra cosa (o simplemente la cosa, la cuestión que en cualquier caso es cuestión) se abra paso a través de lo allanado, a saber, el sýmbolon, lo simbólico. Tanto es así que la definición del signo lingüístico (la correspondencia biunívoca entre significante y significado) solo se constata en cómo ocurren las respuestas normales en contextos de habla normales entre hablantes nativos. Lo que se observa a simple vista no es que sonidos se conecten a significados, sino que se anda trabado en esa correspondencia biunívoca tal que si alguien me dice “¿me pasas el pan, por favor?”, sin decir nada más, le acercaré el pan. Y es a esto a lo que llamamos estar referidos a las cosas tal que la semántica que hay en ello ha salvaguardado la del griego semaínein o hermeneía.

Sin embargo, allanamiento también significa vaciar la cualificación, descualificar las cosas, irrumpir en la dignidad de la cosa como se irrumpe en la intimidad (y seguridad) del hogar. Esta violencia también está presente en la tematización a la que nos referimos más arriba y el mismo mecanismo se encuentra en la constitución de la lingüística. La fundamentación del signo lingüístico significa que no hay ningún corte del conjunto significante de una lengua, ni tampoco ningún corte del conjunto significado de esa lengua, que de antemano esté cualificado (señalado) frente a todos los demás, y esto es condición de la posibilidad de que haya signo lingüístico. Pero, además, de ello se sigue que tampoco hay de antemano signos lingüísticos más relevantes, señalados o cualificados que otros, sino que todo signo lingüístico es, por principio, equivalente a cualquier otro y lo único que hace que luego la lingüística pueda clasificarlos es el tipo de relación funcional que cumplen entre sí en un contexto de habla de una lengua; contexto que es, a su vez, donde luego es posible que algún signo quede cualificado.

Esta violencia inherente al allanamiento -este aspecto peyorativo, si se quiere decir así, del término que, en cierto modo, afea la intención aséptica del discurso filosófico e introduce un vector de ambigüedad- se muestra especialmente en cierto problema que el lingüista no siempre nota $-\mathrm{y}$ no tiene porqué notarlo, es decir, no es un problema del cual el lingüista pueda, pero tampoco del que tenga que ocuparse-, pero que es consustancial a que la misma lingüística se constituya como ciencia. Podemos apreciarlo volviendo sobre algo que se dijo como de pasada en el apartado anterior, a saber, que lo lingüístico solo se define enfrentándose a lo nolingüístico, a lo extralingüístico (e implícitamente, siempre quedó como el continuo ilimitado del que siempre se partía, ya fuese en dirección al significado o en dirección al significante) y para ello la lingüística recurre al concepto de estructura. Esto acarrea que todo eso de lo que la lingüística no debiera ocuparse (que si se repasa la argumentación es, en definitiva, todo el ámbito de lo ente y nuestro estar referidos a ello), no debiera, a su vez, estar incluido en nada de lo lingüístico.

Sin embargo, dado que el estatuto de las entidades lingüísticas es estructural, no se pueden observar más que allí donde se realizan, es decir, en su tener lugar, en la conducta misma de los hablantes, realización que siempre es en estos o aquellos "reales", en estas o aquellas "cosas" observables y determinables desde la física-matemática. Por consiguiente, terminaba resultando que la distinción entre lo "lingüístico" y lo "extralingüístico” solo obedecía a cómo había que reconocer lo lingüístico mismo, pero no a que, en efecto, hubiera un "extralingüístico" para la lingüística, ni porque la "entidad lingüística” fuese un tipo de entidad reconocible sin todo el aparataje conceptual que la lingüística pone en marcha; lo cual es algo así como que no haya nada por fuera de lo lingüístico.

Esto no debe confundirse con un ingenuo panlingüismo o un holismo lingüístico; la cuestión es más grave, porque ese reconocimiento de que no hay nada fuera de lo lingüístico se hace desde el supuesto reconocimiento de lo extralingüístico y para definir con claridad el ámbito concreto y autónomo de lo lingüístico distinguiéndolo de todo lo demás con criterios normativos. El problema, digo, es que es esa marcha la que termina por decir que ese campo es todo el campo, es decir, es esa marcha la que muestra que lo que hay detrás, lo que ha sucedido ya siempre (digamos, siempre que se inicia la argumentación) es el allanamiento de cualquier 
rastro de relevancia en las cosas (en lo ente); de manera que es esa ausencia de relevancia, de presencia cualificada, la que exige, por un lado, cómo debe fundamentarse la lingüística y, por otro, que no haya nada que pueda resistir a terminar por ser incluido en aquello de lo que el lingüista tiene que ocuparse (sonidos, conductas, presupuestos del contexto, etc.).

La lingüística no puede hacer mucho más; tiene que dar un salto y no extender su argumento hasta las últimas consecuencias ${ }^{14}$. Seguido el argumento hasta las últimas consecuencias, esta ciencia tiene que constituirse dejando fuera a todo lo ente, para una vez conquistada su zona, sus entidades (lingüísticas), notar que esas entidades se observan en la marcha de todo lo que hay, de manera que, en cierto modo, son todo lo que hay. No porque lo que hubiera (todo eso que se dejó fuera y luego resultó que era aquello que observaba) ahora esté dentro, sino porque termina por reconocer que no había ni "dentro" ni "fuera”, sino solo lengua en su hablarse. Aunque ningún lingüista cabal diga nada parecido a lo que se acaba de formular, es lo que se sigue de los monumentos teóricos de fundamentación más importantes de esta ciencia, y esto es lo grave. Lo grave es que la fundamentación de la lengua como objeto de estudio de una ciencia desemboque en que todo sea de la lengua.

Pues bien, en la filosofía de Heidegger puede encontrarse un modo de afrontar este problema y de darle una salida más o menos digna. Veámoslo brevemente.

\section{Referirnos a las cosas}

La aclaración que Heidegger da a la palabra sýmbolon no se queda en las expresiones de la juntura, la soldadura o la articulación, ni siquiera en la del mantenerse-junto que es un convenio de dos cosas. En la economía interna del curso en el que encontramos el tramo textual que se ha comentado, todo esto aparece en función de cierto trazado más o menos definido de una distinción entre el "animal” y el "hombre”, la cual está, a su vez, en función de explicitar el término "mundo" que Heidegger trata de elevar a "concepto" (en el sentido de indicación formal); esa distinción tiene, por consiguiente, un papel heurístico o expositivo de cuestiones como las que se han comentado (o así se lo está leyendo aquí).

Luego, esa comparación no constituye el tema para los presentes intereses, sino, por así decir, la excusa para llegar al tema ${ }^{15}$. Pues bien, en este contexto, a propósito del "suceder símbolo” se hace notar lo siguiente:

Tal suceder falta en el animal, que de todos modos produce sonidos. Estos sonidos indican algo, como decimos, dan noticia de algo, y sin embargo las emisiones no son palabras, no tienen significado, no pueden dar a significar nada. Ello solo lo posibilita la génesis del símbolo, todo el suceder en el que sucede de entrada un mantenerse junto, un mantenerse junto el hombre con algo, de tal modo que el hombre, con aquello con lo que se mantiene junto, puede convenir en el modo del mentar. El hombre se mantiene, y de hecho conforme a su esencia, junto con otra cosa, en tanto que se comporta respecto de otro ente y precisamente por ese comportamiento respecto de otra cosa puede mentar eso otro en cuanto tal (GA 29/30, p. 446).

Con esto se pone de manifiesto que el "suceder símbolo" es otro modo de mencionar no solo el aspecto diferenciado del discurso, sino el que el Dasein consista en un siempre ya encontrarse afectivamente (receptivo de lo que ocurra a su alrededor en sentido amplísimo), comprendiendo

14 Me refiero aquí a aquellas fundamentaciones cabales, aquellas que, por así decir, saben que la caída de una piedra no es nada lingüístico, pero que es solo a razón de que se está hablando una lengua, que puede llegar a haber una conceptualización de todo lo que implica ese "caerse de una piedra”.

15 Esto no quiere decir que no haya el tema del animal, o que no se lo pueda leer en Heidegger; para una lectura de ello, véase el trabajo de F. Rodríguez, Cantos Cabríos (Rodríguez, 2015, pp. 251-300), especialmente el apartado “2.3. Y sin embargo, no: los perros no existen (Heidegger / The Lord of the Ring)", (Rodríguez, 2015, pp. 266274). 
y discurriendo (articulando esa comprensión en su ya encontrarse afectivo); por tanto, es un modo de referirse a que haya encontrarse (Befindlichkeit), entender o comprender (Verstehen) y habla o discurso (Rede) del Dasein. Pues nótese que Heidegger no solo menciona el que haya dos cosas -como ocurría en el ejemplo del anillo dividido y los hijos de los padres de tal modo hermanados-, sino el que ocurra de entrada ese mantenerse junto el hombre con algo. Lo mantenido junto no es, por ejemplo, este ordenador en el que escribo con la articulación sonora de los fonemas implicados en la mención de “ordenador", sino este ordenador conmigo (que tiene que poder ser cualquiera) en mi encontrarme afectivamente en algún tono escribiendo (comprendiendo o entendiendo en ello de escribir) tal que cabe que esto mismo pueda ser articulado e incluso comunicado ("heme aquí, escribiendo en mi ordenador...”). ¿Qué se está mostrando con esto? ¿Qué fenómeno nos está saliendo a la luz? ¿No se está tematizando justamente eso por lo que antes preguntábamos, el que nos refiramos a las cosas que también encontramos en la lingüística, pero como el problema de lo "extralingüístico” (y añadimos las comillas porque ya sabemos que, en el fondo, no es nada, no lo hay)?

Recordemos ahora que aquel problema sucedía para la lingüística en coherencia con que tuviese que echar mano del término estructura, el cual le servía para identificar el carácter de lo que sí le pertenecía. Lo “extralingüístico” era lo que no dependía de identificar esa estructura y, por ello, este término está más marcado en lingüística que, por ejemplo, en el contexto del formalismo matemático (que lo usa en el mismo sentido), donde no hace falta definir nada “extramatemático". Insisto en que esto se reconoció, de todas formas, como un problema que el lingüista ni resuelve, ni tiene porqué resolver, lo cual quiere decir que esta ciencia funciona a pesar de ello: las definiciones se sostienen, sus conceptos operan y sus análisis dan resultados. Donde sí puede ser muy notorio es en el discurso filosófico, pues es desde este discurso que se reconoce una suerte de salto en este punto. No quiero dejar de insistir en que, a pesar de todo, por este salto hay que pasar para que la lingüística sea sostenible. Y, sin embargo, este salto pone en cuestión su carácter primario u originario para afrontar la tarea de decir, de tematizar qué es la lengua y el lenguaje, al mismo tiempo que reconoce que, de todas formas, no nos queda más remedio que empezar por ello, que empezar por entender en qué consiste la lingüística.

Pues bien, este salto se aclara constatando, a partir de lo que el análisis de Heidegger hace notar, que consiste en que nos hallamos ya siempre comprendiendo las cosas en medio de las cuales nos encontramos afectivamente y con las que estamos articulados de modo que, por ello mismo, podemos mentar esto o lo otro, o sea, discurrir; eso es, por así decir, por encima de lo cual tiene que saltar la lingüística. Esto mismo encuentra, además, cierta traslación (en sentido fuerte) de lo que significa el suceder símbolo: "Lo que, de modo totalmente oscuro y casual y sin ninguna explicación, Aristóteles ve con una mirada genial bajo el título de $\sigma 0 ́ \mu \beta 0 \lambda o v$ no es otra cosa que lo que nosotros llamamos hoy la transcendencia” (GA 29/30, p. 447); de lo cual podemos decir que la noción de transcendencia es lo que significa el que estemos ya siempre referidos a las cosas.

Así, por transcendencia se está entendiendo lo que acabamos de expresar como el salto no tematizado por la lingüística y que al tematizarlo pone en cuestión su carácter originario; pero que, en la medida en que, para esa tematización, se echa mano de ella, se muestra que tampoco hay otra cosa en la que luego instalarse. No hay, por así decir, nada después de la lingüística, sino tan solo el constante esfuerzo por ganar la distancia suficiente como para comprenderla. Heidegger no lo expresa así, pero sí dice que: "Sólo hay lenguaje [Sprache] en un ente que, conforme a su esencia, transciende” (GA 29/30, p. 447), es decir, en un ente que consiste en comprender sentido de ser (del "ser” de esto o aquello) y cuyo “negocio” de sí mismo está en 
ese “a dónde” trasciende y en cómo y desde dónde se puede entender ese "a dónde”, a saber, en qué consiste el punto de partida de ese mundo en que $e s^{16}$.

Ahora bien, insisto de nuevo, esa transcendencia no es, como sí era el "suceder símbolo" en Aristóteles, nuestro punto de partida, sino el de llegada, lo que solo se logra mediante el análisis fenomenológico hermenéutico. Pero ¿dónde se volvió a reconocer esta transcendencia? ¿Dónde se volvió a recurrir a la palabra "símbolo" para expresar justamente lo que Heidegger expresa con esta palabra?

\section{A modo de conclusión: el allanamiento simbólico}

No pregunto acerca de qué fenomenólogos o hermeneutas tematizaron esto (digamos que ese es aquí Heidegger), sino en qué contexto se tuvo que utilizar la palabra "símbolo" tal que no se la asumía como la "representación de...", sino justamente como lo que se acaba de exponer y comprendiendo todo lo que se acaba de exponer. Es más, lo pregunto pretendiendo con ello notar que ese contexto tampoco se entiende como tal sin lo que se acaba de exponer, tanto por lo que refiere al resumido recordatorio de lingüística como al trabajo fenomenológicohermenéutico de Heidegger sobre Aristóteles. Este no será un lugar que pretendidamente haya hecho esta conexión, sino un lugar que no haya tenido más remedio que salir del paso porque alguna experiencia se le imponía más allá de lo que sus conceptualizaciones le permitían.

Pues bien, ese lugar es aquel en el cual la mentada experiencia era una en la que sí que podía decirse que todo se jugaba en el hablar de una lengua, incluso (y con esto casi lo hemos dicho ya), de una lengua de la que nadie sabe, en principio, nada. Me refiero a la experiencia psicoanalítica, a ese discurso que se ha llamado "psicoanálisis” y que quizá todavía esté por leerse como, por ejemplo, Heidegger leyó a Aristóteles (Fasolino, 2019). Y afirmo que es este el lugar porque es en esa práctica donde uno de aquellos que asumió llamarse "psicoanalista" terminó por hablar de cierto registro simbólico del discurso, tal que el uso del adjetivo "simbólico" ya no podía significar lo que se dijo que normalmente se entiende cuando alguien dice que tal cosa "simboliza” tal otra (cf. Lacan, 1999, pp. 175-195). Nos referimos a Lacan, y, para que no hubiese ninguna duda, a eso que normalmente se entiende por "simbolizar", en el sentido del “representar”, lo llamó, más bien, registro imaginario del discurso.

Pues bien, dado que es en ese registro en el que el psicoanalista se juega sus cuartos (que son los del paciente, pero que en la medida en que es el psicoanalista el que se responsabiliza de ellos, son los suyos), pues es de este registro del que depende que un análisis llega a ser ese extraño (o siniestro) "éxito" que puede ser para el sujeto enfermo, o ese desastroso estropicio que desencadene todavía más dolor y padecer, es importante notar que el allanamiento del sýmbolon ha resultado en que sea precisamente ese el registro decisivo (lo cual no quiere decir que los otros no sean importantes, ni siquiera que puedan darse los unos sin los otros). Y que sea ese no quiere decir que el sýmbolon no esté allanado, sino que lo que debemos notar nosotros es que lo allanado ha llegado a ser para nosotros ese registro, el allanamiento lo es de lo simbólico. Lo cual quiere decir justamente que de lo que se trata es de ese allanamiento, de que está ahí y de que hay que reconocerlo, pues es en eso, en que, por así decir, este terreno se allane, en lo que nos jugamos los cuartos no ya de “extraños o siniestros éxitos” o “desastrosos estropicios”, sino de comprender sentido de ser, el sentido de nuestro a dónde de la trascendencia, es decir, donde nos jugamos entender de nuestro mundo.

16 Véase en los parágrafos 11, 12 y 13 del curso de Heidegger de 1928 sobre Leibniz (GA 26, pp. 203-284). 


\section{Referencias}

AUBENQUE, Pierre (2013): Le problème de l'être chez Aristote, 6a ed., Presses Universitaire de France, Paris.

BAILLY, Anatole (1950): Dictionnaire Grec - Français. Rédigé avec le concours de E. Egger. Édition revue par L. Séchan et P. Chantraine ; avec une appendice de nouvelles notices de mythologie et religion par L. Séchan, Librairie Hachette, Paris.

BÜHLER, Karl (1999): Sprachtheorie, $3^{\text {a }}$ ed., Lucius \& Lucius, Stuttgart.

CHAMPBELL, Scott M. (2007): "Revelation and Concealment in the Early Heidegger's

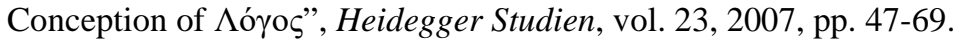

COURTIN, Jean Fraçois (2018): "Heidegger: La construcción de la ontoteología”, en R. rodríguez (ed.), Guía Comares de Heidegger, Editorial Comares, Granada, pp. 315-336.

CHILLÓN, José Manuel (2014): “Necesidad y virtud de la comunicación. A propósito de Pol. 1253a de Aristóteles”, Dilemata, $\mathrm{n}^{\circ}$ 14, pp. 61-83.

CHILLÓN, José Manuel (2015): “Ser, conocimiento y lenguaje en De Int. 16a 3. Rudimentos para una Teoría del significado en Aristóteles”, Revista di Filosofía Neo-Scolastica, no. 3, pp. 501-519.

CURRÁS RÁBADE, Ángel (1977): “Heidegger: el arduo sosiego del exilio”, Logos. Anales del seminario de metafísica, vol. 12, pp. 59-94.

DE SAUSSURE, Ferdinand (2005): Cours de linguistique général. Publié par Charles Bally et Albert Séchehaye avec la collaboration de Albert Riedlinger (1916). Édition critique préparée par Tullio de Mauro (1967), trad. Louis-Jean Calvet). Postface de Louis-Jean Calvet, Éditions Payot \& Rivages, Paris.

FASOLINO, Rubén Carmine (2019): “Aclaraciones hermenéuticas a la noción de "significante” en Lacan”, Logos. Anales del Seminario de Metafísica, vol. 52, pp. 51-67.

HEIDEGGER, M., GA 5, Holzwege, ed. Friedrich-Wilhelm von Herrmann, Frankfurt, V. Klostermann Verlag, 1977.

HEIDEGGER, M., GA 7, Vorträge und Aufsätze, ed. Friedrich-Wilhelm von Herrmann, Frankfurt, V. Klostermann Verlag, 2000.

HEIDEGGER, M., GA 9, Wegmarken, ed. Friedrich-Wilhelm von Herrmann, Frankfurt, V. Klostermann Verlag, 1976.

HEIDEGGER, M., GA 21, Logik. Die Frage nach der Wahrheit, ed. Walter Biemel, Frankfurt, V. Klostermann Verlag, 1976.

HEIDEGGER, M., GA 26, Metaphysische Anfangsgründe der Logik im Ausgang von Leibniz, ed. Klaus Held, Frankfurt, V. Klostermann Verlag, 1978.

HEIDEGGER, M., GA 19, Platon: Sophistes, ed. Ingeborg Schüßler, Frankfurt, V. Klostermann Verlag, 1992

HEIDEGGER, M. GA 29/30, Die Grundbegriffe der Metaphysik. Welt - Endlichkeit Einsamkeit, ed. Friedrich-Wilhelm von Herrmann, Frankfurt, V. Klostermann Verlag, 2a ed. revisado, 1992.

JIMÉNEZ REDONDO, Manuel (1997): “Sujeto y predicado en Aristóteles y en Heidegger”, Eutopias, Documento de trabajo 157, Episteme, Valencia.

LACAN, Jacques (1999): Écrits II, nouvelle édition, Éditions du Seuil, Paris.

MARTÍNEZ MARZOA, Felipe (1996): Heidegger y su tiempo, Akal, Madrid.

MARTÍNEZ MARZOA, Felipe (1999): Lengua y tiempo, Visor, Madrid.

MARTÍNEZ MARZOA, Felipe (2001): Lingüística fenomenológica, Visor, Madrid.

MARTÍNEZ MARZOA, Felipe (2019): Hojas, Abada Editores, Madrid.

MORENO TIRADO, Guillermo (2020): El allanamiento del lenguaje. Un estudio a partir de la obra de M. Heidegger. Tesis inédita de la Universidad Complutense de Madrid, Facultad 
de Filosofía, Departamento de Lógica y Filosofía Teórica, leída el 18-11-2019. Disponible en: https://eprints.ucm.es/59432/1/T41812.pdf [2020, 24 de abril]

RODRÍGUEZ, Federico (2015): Cantos cabríos. Jacques Derrida, un bestiario filosófico, Fondo de Cultura Económica, Santiago de Chile.

SEGURA PERAITA, Carmen (2002): Hermenéutica de la vida humana. En torno al informe Natorp de Martin Heidegger, Trotta, Madrid.

SEGURA PERAITA, Carmen (2015): "Heidegger en torno a Aristóteles. Una mirada fenomenológico-hermenéutica”, Contrastes, Vol. 20, no. 2, pp. 231-249.

SEGURA PERAITA, Carmen (2018): “Asimilación, destrucción y apropiación de algunos conceptos fundamentales de la filosofía aristotélica”, R. Rodríguez (ed.): Guía Comares de Heidegger, Editorial Comares, Granada, pp. 337-357.

TAMINIAUX, Jacques (1989): Lectures de l'ontologie fondamentale: essai sur Heidegger, Jérôme Million, Grenoble.

VIGO, Alejandro (2008): Arqueología y aleteiologia y otros estudios heideggerianos. Editorial Biblios, Buenos Aires.

VIGO, Alejandro (2012): "Categorías y experiencia antepredicativa en el entorno de Sein und Zeit”, Studia Heideggeriana, Vol. 2, Lógos - Lógica - Lenguaje, ed. Francisco de Lera, Editorial Teseo, Buenos Aires, pp. 71-128.

VIGO, Alejandro (2013): Juicio, experiencia, verdad. De la lógica de la validez a la fenomenología, Ediciones Universidad de Navarra, Barañáin.

VILLAVERDE LÓPEZ, Guillermo (2017): “Consideraciones en torno a la noción de estructura y la época moderna”, A. Leyte (ed.), La historia de la nada. 14 ensayos a partir del pensamiento de Felipe Martínez Marzoa, La oficina, Madrid, pp. 109-134.

VOLPI, Franco (1984): Heidegger e Aristotele, Daphne Editrice, Padova. 